\title{
Behaviour of 316L Stainless Steel containing Corrosion Pits under Cyclic Loading
}

DOI:

10.1002/maco.201810744

\section{Document Version}

Accepted author manuscript

Link to publication record in Manchester Research Explorer

\section{Citation for published version (APA):}

Hashim, M., Farhand, F., Smyth-Boyle, D., Akid, R., Zhang, X., \& Withers, P. (2019). Behaviour of 316L Stainless Steel containing Corrosion Pits under Cyclic Loading. Materials and Corrosion, 1.

https://doi.org/10.1002/maco.201810744

\section{Published in:}

Materials and Corrosion

\section{Citing this paper}

Please note that where the full-text provided on Manchester Research Explorer is the Author Accepted Manuscript or Proof version this may differ from the final Published version. If citing, it is advised that you check and use the publisher's definitive version.

\section{General rights}

Copyright and moral rights for the publications made accessible in the Research Explorer are retained by the authors and/or other copyright owners and it is a condition of accessing publications that users recognise and abide by the legal requirements associated with these rights.

\section{Takedown policy}

If you believe that this document breaches copyright please refer to the University of Manchester's Takedown Procedures [http://man.ac.uk/04Y6Bo] or contact uml.scholarlycommunications@manchester.ac.uk providing relevant details, so we can investigate your claim.

\section{OPEN ACCESS}




\section{Behaviour of 316L Stainless Steel containing Corrosion Pits under Cyclic Loading}

\begin{tabular}{|r|l|}
\hline Journal: & Materials and Corrosion \\
\hline Manuscript ID & maco.201810744.R2 \\
\hline Wiley - Manuscript type: & Article \\
\hline Date Submitted by the \\
Author: & 15 -May-2019 \\
\hline Complete List of Authors: & $\begin{array}{l}\text { Hashim, Muntasir; The University of Manchester, School of Materials; } \\
\text { TWI Ltd, NDT } \\
\text { Farhand, Farnoosh; Coventry University Faculty of Engineering and } \\
\text { Computing } \\
\text { Smyth-Boyle, David; TWI Ltd, } \\
\text { Akid, Robert; Materials } \\
\text { Zhang, Xiang; Coventry University Faculty of Engineering and Computing } \\
\text { J. Withers, Philip; The University of Manchester, School of Materials }\end{array}$ \\
\hline Keywords: & \begin{tabular}{l} 
Corrosion pits, FEA, fatigue, pit-crack transition, 316L stainless steel \\
\hline
\end{tabular} \\
\hline
\end{tabular}

\section{SCHOLARONE Manuscripts}




\title{
WILEY-VCH
}

\section{Article type: Article}

\section{Behaviour of 316L Stainless Steel containing Corrosion Pits under Cyclic Loading}

Muntasir Hashim ${ }^{1,2,3}$, Farnoosh Farhad ${ }^{1,4}$, David Smyth-Boyle ${ }^{3}$, Robert Akid ${ }^{2}$, Xiang Zhang ${ }^{4}$, Philip J. Withers ${ }^{2}$

1- National Structural Integrity Research Centre (NSIRC), Cambridge, UK

2- University of Manchester, Manchester, UK

3- TWI Ltd., Cambridge, UK

4- Faculty of Engineering, environment and Computing, Coventry University, Coventry, UK

\section{Correspondence}

Muntasir Hashim, TWI Ltd, Granta Park, Great Abington, Cambridge CB21 6AL, United Kingdom

Email: Muntasir.Hashim@twi.co.uk,

\begin{abstract}
:
The environmental performance of $316 \mathrm{~L}$ grade stainless steel, in the form of tensile specimens containing a single corrosion pit with various geometries, under cyclic loading in aerated chloride solutions is investigated in this work. Results from environmental tests were compared and contrasted with those obtained using finite element analysis (FEA). Fractography of the failed specimens obtained from experiments revealed that fatigue crack initiation took place at the base of the shallow pit. The crack initiation shifted towards the shoulder and the mouth of the pit as the pit depth increased. This process is well predicted by FEA, as the strain contour maps show that strain is the highest around the centric strip of the pit. However, for shallow pits, local strain is uniformly distributed around that strip but begins to concentrate more towards the shoulder and the mouth region as the pit increases in depth.
\end{abstract}

Keywords: Corrosion pits, FEA, fatigue, pit-crack transition, 316L stainless steel 


\section{WILEY-VCH}

\section{Introduction}

Pitting corrosion is a localised damage mechanism that can occur on the surface of many metal alloys. The process can be defined as the accelerated local dissolution of metal, occurring as a result of the breakdown of the otherwise protective passive film present on the metal surface, thus leading to small cavities ('pits'). Pitting is more difficult to detect, predict and design against in comparison to uniform corrosion and as such is considered more dangerous. The morphology of pits may vary considerably, in terms of geometric shape and depth-width (aspect) ratio. Pits propagate with complex directionality, as a function of local stress, microstructure and pit chemistry. Pitting corrosion is particularly problematic for structures operating in marine environments, due to the presence of high concentrations of metal chlorides $\left(\mathrm{NaCl}, \mathrm{MgCl}_{2}\right.$ and $\mathrm{CaCl}_{2}$ ), which are aggressive to steel alloys. Pits can act as local stress raisers in a material and hence can participate in the failure of a material through fatigue and/or stress corrosion cracking (SCC) mechanisms. Consequently, research focussed on defining the range of conditions for which pitting might occur during operational life, allied with determination of the probability of the pit to crack transition, has significant potential to improve material selection at the design stage and structural integrity in general.

Pitting corrosion fatigue life consists of pit initiation, pit growth, crack initiation and crack growth to final failure [1,2]. The available fatigue crack initiation models [2-8] are in fact based on the crack propagation approach, rather than initiation, as they assume a pit to behave as a small crack and use transition criterion to predict the pit-to-crack transition. This criterion uses the stress intensity factor as described by linear elastic fracture mechanics (LEFM), which is valid only when the yield zone ahead of crack is small. Due to the possible large size of the plastic zone around corrosion pits, the possibility of pit local stress to be the driving force for crack initiation, rather than stress intensity factor, is significant. More specifically, the small- 


\section{WILEY-VCH}

scale yielding and linear elastic assumption may be unrealistic for crack initiation prediction models as applied to pits [9]. In this paper, we assume that a pit can be considered as a notch, i.e. a stress raiser, rather than a crack.

For fatigue life prediction of a material, the pit-to-crack transition stage possesses significant challenges. The transition from a pit-to-crack is not well understood and the early stages of crack development lacks significant insight, leading to uncertainty of both the location of crack nucleation from the pit and the conditions producing crack nucleation. Previous studies [6] have generally assumed that cracks initiate from the base of the corrosion pit, but Turnbull et. al. $[10,11]$ has shown that this is not always the case, as these workers found that the majority of the cracks initiated near the mouth of the corrosion pits.

In the work described herein, we have performed corrosion fatigue tests and supplementary FEA to compare and contrast with the results of tests to better interpret the pit-to-crack process. Single corrosion pits of varying aspect ratios (depth-to-width) were grown on lab specimens made of 316L grade stainless steel (SS 316L) and exposed them to aerated saline solutions under cyclic loads. Surface analysis was carried out on the failed specimens using a scanning electron microscope (SEM) to determine the location of the crack initiation site and crack path for a given geometry of corrosion pit. The local stress field at the pit under cyclic load was studied using finite element analysis (FEA). The pit geometries used for FEA modelling here are similar in terms of aspect ratio to those generated during experiments. Previous studies have used FEA to study the pit-to-crack transition under static loading using the elastic and elasticplastic material models $[1,10,12-20]$. Other than a study by some of the authors of the present work [21], we are not aware of any other published data on finite element analysis of corrosion pits under cyclic loading in air or in environment. 


\section{WILEY-VCH}

The approach of using empirical studies to generate test data and complementary FE modelling has allowed us to better understand the pit-to-crack damage phenomena. We have reviewed the strain localisation determined by FEA models in the context of the observed crack initiation site(s) on specimens, to propose a fatigue crack initiation process based on the available physical evidence.

\section{Methodology}

The effect of cyclic loading of $316 \mathrm{~L}$ specimens containing a single corrosion pit was investigated through corrosion fatigue testing and corresponding FEA. Three pit geometries with different aspect ratios are used in this study. The aspect ratio of the corrosion pits in this work is described in Figure 1.

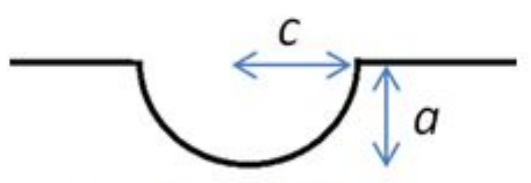

Aspect Ratio $(A R)=a / c$

Figure 1: Pit geometry in this work is defined as shown in terms of the aspect ratio (AR). $\mathrm{AR}<1$ is termed shallow, $\mathrm{AR}=1$ is symmetrical and $\mathrm{AR}>1$ is considered a deep pit.

\subsection{Experiments}

\subsubsection{Material}

The chemical composition of $316 \mathrm{~L}$ alloy used in this work is given in Table 1 . The mechanical properties of the material were derived through tensile testing in accordance with ISO 6892-1 standard. Average values of $230 \mathrm{MPa}$ (YS at $0.2 \%$ offset) and $595 \mathrm{MPa}$ (UTS) were determined.

Table 1: The chemical composition of SS 316L used in this work

\begin{tabular}{|l|l|l|l|l|l|l|l|l|l|l|l|}
\hline \multicolumn{2}{|l|}{ Chemical, $(\% \mathrm{~m} / \mathrm{m})$} \\
\hline $\mathrm{C}$ & $\mathrm{Si}$ & $\mathrm{Mn}$ & $\mathrm{P}$ & $\mathrm{S}$ & $\mathrm{Cr}$ & $\mathrm{Mo}$ & $\mathrm{Ni}$ & $\mathrm{Al}$ & $\mathrm{As}$ & $\mathrm{B}$ & $\mathrm{Co}$ \\
\hline 0.015 & 0.40 & 1.39 & 0.025 & 0.003 & 17.0 & 2.10 & 10.1 & $<0.01$ & 0.008 & 0.002 & 0.009 \\
\hline
\end{tabular}




\section{WILEY-VCH}

\begin{tabular}{|l|l|l|l|l|l|l|l|}
\hline $\mathrm{Cu}$ & $\mathrm{Nb}$ & $\mathrm{Pb}$ & $\mathrm{Sn}$ & $\mathrm{Ti}$ & $\mathrm{V}$ & $\mathrm{W}$ & $\mathrm{Ca}$ \\
\hline 0.22 & $<0.01$ & 0.002 & 0.010 & $<0.005$ & 0.02 & $<0.05$ & $<0.001$ \\
\hline
\end{tabular}

Samples were machined using electrical discharge machining (EDM) with dimensions as shown in Figure 2 and in accordance with the requirements of ASTM E466 for fatigue testing.

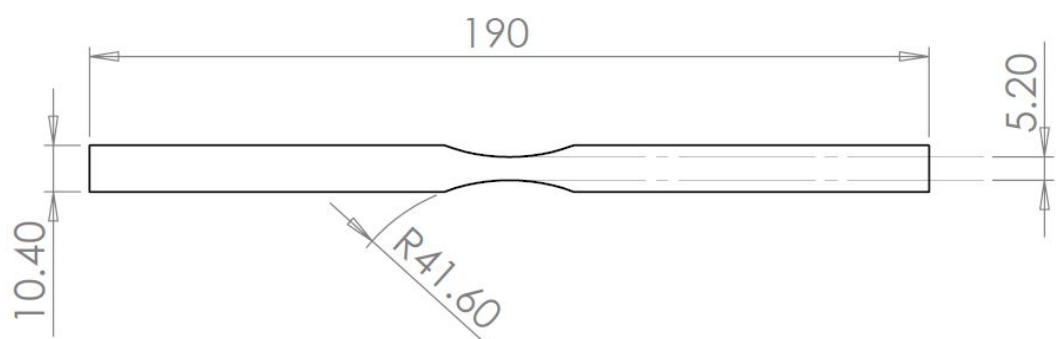

Figure 2: Dimensions, in $\mathrm{mm}$, of the specimens used for fatigue testing

Following the machining process, surfaces of the samples were ground to 1200 grit finish using grit papers and then polished using $6 \mu \mathrm{m}, 3 \mu \mathrm{m}$ and finally $1 \mu \mathrm{m}$ synthetic diamond compound. This process ensured a satisfactory surface finish for test specimens, with average surface roughness values $(\mathrm{Ra})$ of $0.095 \mu \mathrm{m}$. Residual stress measurements using X-ray diffraction were carried out on the surface of polished samples. Compressive stresses were detected and are presented in Table 2 .

Table 2: X-ray diffraction surface residual stress measurements of 316L SS surface prepared to $\mathrm{Ra} 0.095 \mu \mathrm{m}$.

\begin{tabular}{lll}
\hline & \multicolumn{2}{c}{ Surface Residual Stress, MPa } \\
\hline & Transverse & Longitudinal \\
& (across the long axis of the specimen) & (along the long axis of the specimen) \\
\hline Highest & $-283.78 \pm 35.08$ & $-402.39 \pm 23.31$ \\
Lowest & $-237.61 \pm 21.00$ & $-321.45 \pm 21.02$ \\
\hline
\end{tabular}




\section{WILEY-VCH}

\subsubsection{Pre-Pitting}

A single corrosion pit was grown on the surface of the specimen at the centre of the gauge length using the micro-capillary electrochemical cell technique [22]. Table 3 shows the dimensions of the three types of pits generated for this study as determined initially by confocal light microscopy and subsequently by X-ray tomography using an Xradia Versa 520 instrument.

Table 3: The dimensions of the single corrosion pits generated for this study

\begin{tabular}{llll}
\hline Specimen Number & Diameter, 2c $(\mu \mathrm{m})$ & Depth, $a(\mu \mathrm{m})$ & Aspect Ratio, a/c \\
\hline 1 & 780 & 250 & 0.64 \\
2 & 740 & 340 & 0.92 \\
3 & 760 & 480 & 1.26 \\
\hline
\end{tabular}

2.1.3. Corrosion Fatigue testing

Following generation of the pitted specimen, corrosion fatigue tests were carried out at room temperature using aerated $3.5 \mathrm{wt} \% \mathrm{NaCl}$ solutions and a Perspex environmental cell, as shown in Figure 3. The fatigue test parameters employed were as follows: stress range $(\Delta \sigma)$ of 270 $\mathrm{MPa}$, stress ratio of 0.1 and sinusoidal waveform with frequency $0.5 \mathrm{~Hz}$.

Preliminary corrosion fatigue tests using smooth polished 316L SS specimens (i.e. presenting no corrosion pits or defects) employing same parameters as described above showed no failure up to $10^{6}$ cycles, which defined the fatigue limit to be used in subsequent pit-to-crack tests. Identical test parameters to those used before were selected in order to survey the impact of single corrosion pits on the fatigue performance of pre-pitted 316L SS specimens.

The specimens were run to failure and upon failure, the specimens were removed, rinsed with de-ionised (DI) water and the fracture surfaces investigated using scanning electron microscope (SEM). 


\section{WILEY-VCH}

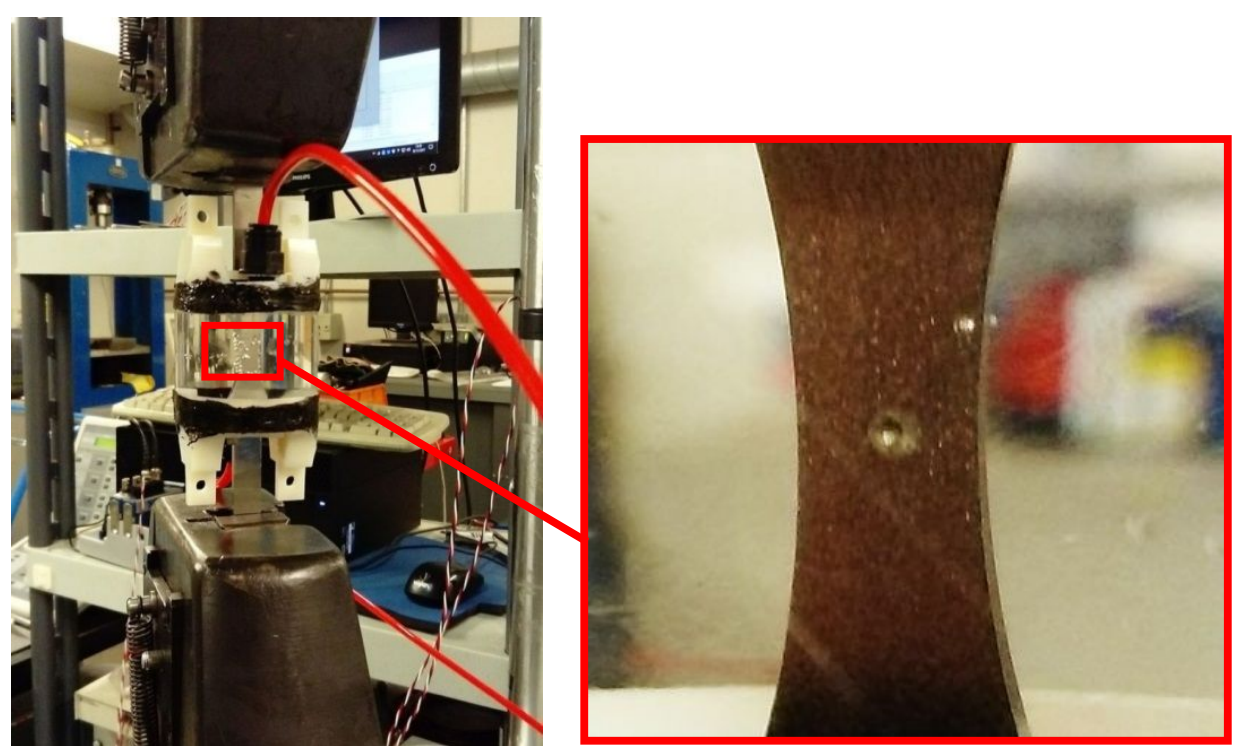

Figure 3 Setup of corrosion fatigue testing of specimens containing a single corrosion pit. The cell contains $3.5 \mathrm{wt} \% \mathrm{NaCl}$.

\subsection{Finite Element Analysis (FEA)}

Many researchers [1, 9, 11-19] have utilised FEA to study the pit-to-crack transition in different alloys, but to-date all studies have been limited to static loading only. In the present study, in order to consider the effect of cyclic loading and local plastic deformation, 3D elastic-plastic FEA has been carried out using ABAQUS software. The local stress-strain behaviour of idealised (i.e. possessing smooth surfaces) pits of three different dimensions was investigated.

To decrease the computation time, quarter-plate geometry including the pit in the centre of the plate was modelled. The size of the model is shown in Figure 4. Table 4 shows the dimensions of created pits. Ten cycles of a sinusoidal load with the same maximum stress and stress ratio as experiments, i.e. $300 \mathrm{MPa}$ and 0.1 , were applied using the 3D model. A combined isotropickinematic hardening elastic-plastic material model was used by implementing the cyclic true stress-strain curve of $316 \mathrm{~L}$ stainless steel, using data provided in the literature [23]. A mesh study was conducted utilising a 10-node second order tetrahedral element (C3D10) to ensure independency of the results with the mesh size. A finer mesh was used around the pit to provide 


\section{WILEY-VCH}

more accurate data in the most important areas. Figure 4 shows the utilised mesh and defined boundary conditions including the symmetry planes.

Table 4: Simulated pit geometries

\begin{tabular}{llll}
\hline Pit number & Diameter, 2c $(\mu \mathrm{m})$ & Depth, $a(\mu \mathrm{m})$ & Aspect ratio, a/c \\
\hline 1 & 750 & 250 & 0.67 \\
2 & 750 & 350 & 0.93 \\
3 & 750 & 450 & 1.2 \\
\hline
\end{tabular}




\section{WILEY-VCH}
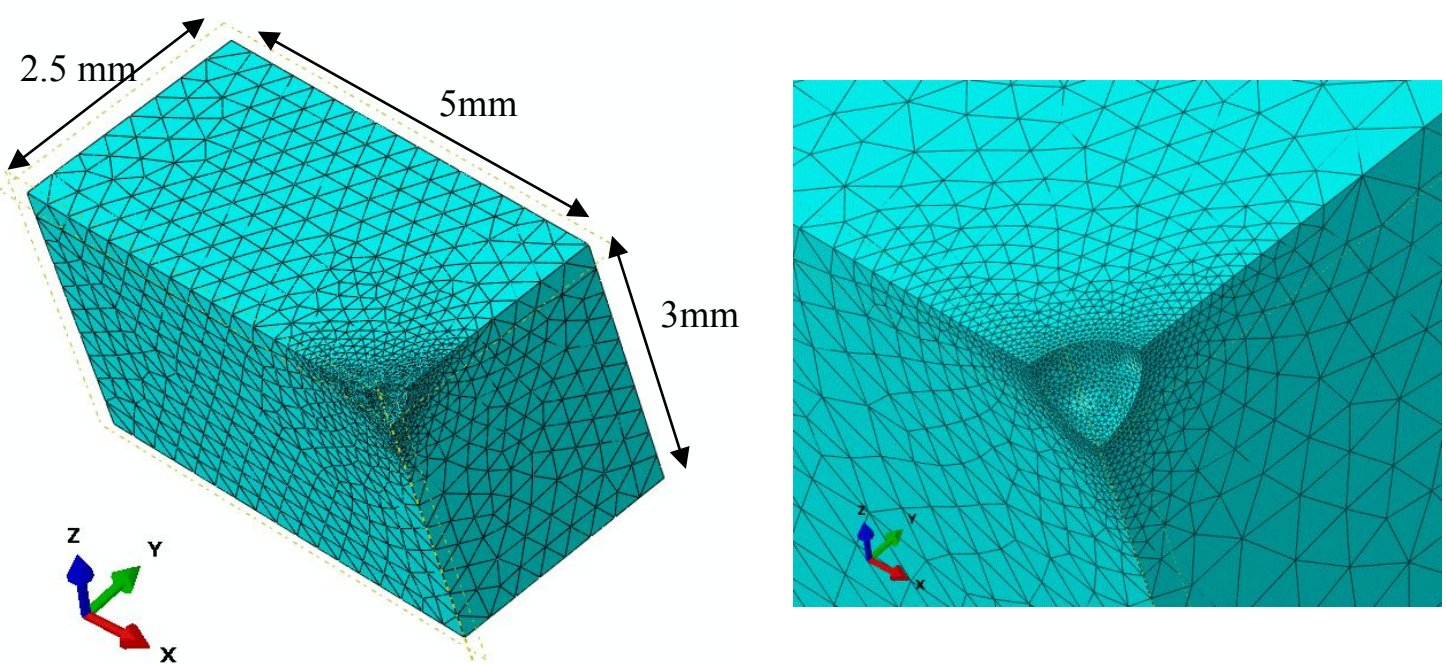

(a)

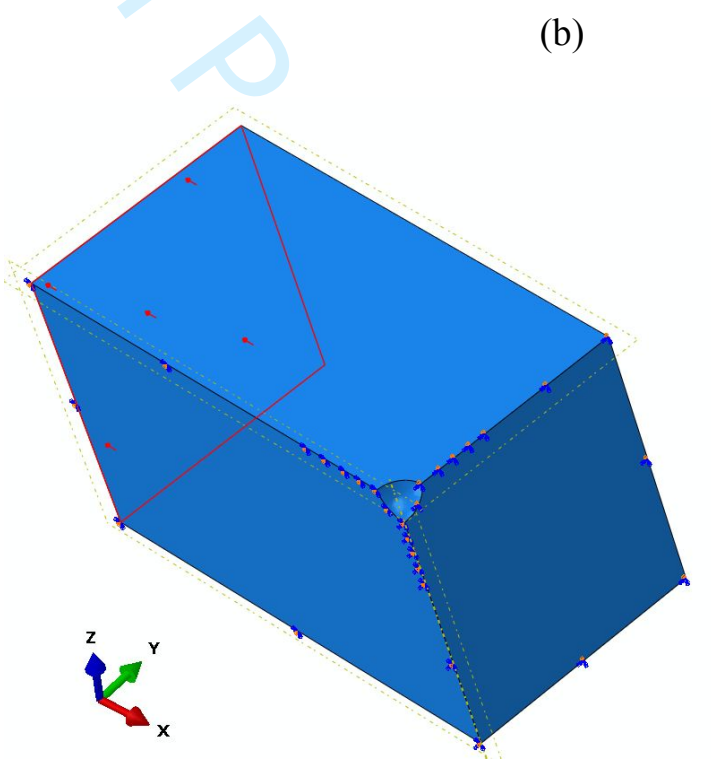

(c)

Figure 4: (a) Finite element model and meshing of 1/4 plate containing a pit. (b) More detailed mesh around the local pit area. (c) Defined boundary conditions including planes of symmetry boundary and applied load. $\mathrm{X}$ is the loading direction.

\section{Results and discussion}

\subsection{Experimental Results}

In these corrosion fatigue tests on 316L SS containing single corrosion pits, it is noted that all cracks leading to the final failure of the specimens originated from corrosion pits. Table 5 contains a summary of test results, including the number of cycles to failure for each specimen 


\section{WILEY-VCH}

containing a single pit with different aspect ratio (Specimen 1; shallow pit; AR $=0.64$ : Specimen 2; quasi-symmetrical pit; $\mathrm{AR}=0.92$; Specimen 3; deep pit; $\mathrm{AR}=1.26$ ). It is clear that as the aspect ratio of the pit increases, the number of cycles to failure decreases.

Table 5: The number of cycles to failure during corrosion fatigue testing of specimens containing single corrosion pits.

\begin{tabular}{lllll}
\hline $\begin{array}{l}\text { Specimen } \\
\text { number }\end{array}$ & $\begin{array}{l}\text { Diameter, 2c } \\
(\mu \mathrm{m})\end{array}$ & $\begin{array}{l}\text { Depth, } a \\
(\mu \mathrm{m})\end{array}$ & $\begin{array}{l}\text { Aspect ratio, } \\
\mathrm{a} / \mathrm{c}\end{array}$ & $\begin{array}{l}\text { Number of } \\
\text { cycles to failure }\end{array}$ \\
\hline 1 & 780 & 250 & 0.64 & 631,357 \\
2 & 740 & 340 & 0.92 & 496,911 \\
3 & 760 & 480 & 1.26 & 120,166 \\
\hline
\end{tabular}

Fractography of the failed specimens was carried out using SEM. The analysis showed that cracks initiated:

- $\quad$ at the base of the shallow pit, AR 0.64

- at the shoulder of quasi symmetrical pit, AR 0.92

- $\quad$ at the mouth of the deep pit, AR 1.26

The location of crack initiation in each case is highlighted in Figures 5-7. 


\section{WILEY-VCH}
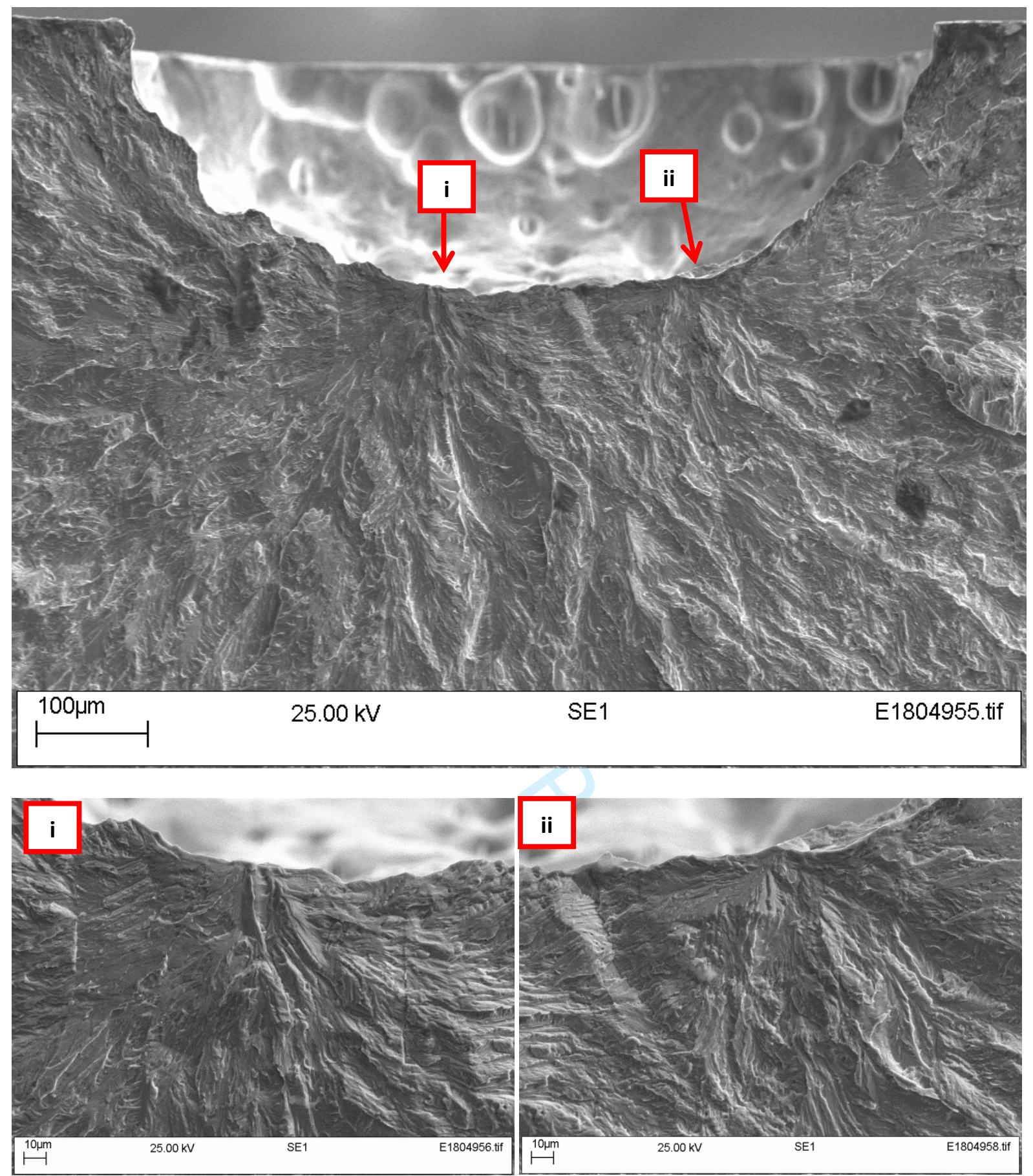

Figure 5: SEM images of crack flank from 'Specimen 1' which had a corrosion pit of AR=0.64. The images emphasize the two crack initiation sites, $i$ and ii being at the base of the corrosion pit. Higher resolution images of sites $i$ and ii where crack initiated are also provided. 


\section{WILEY-VCH}
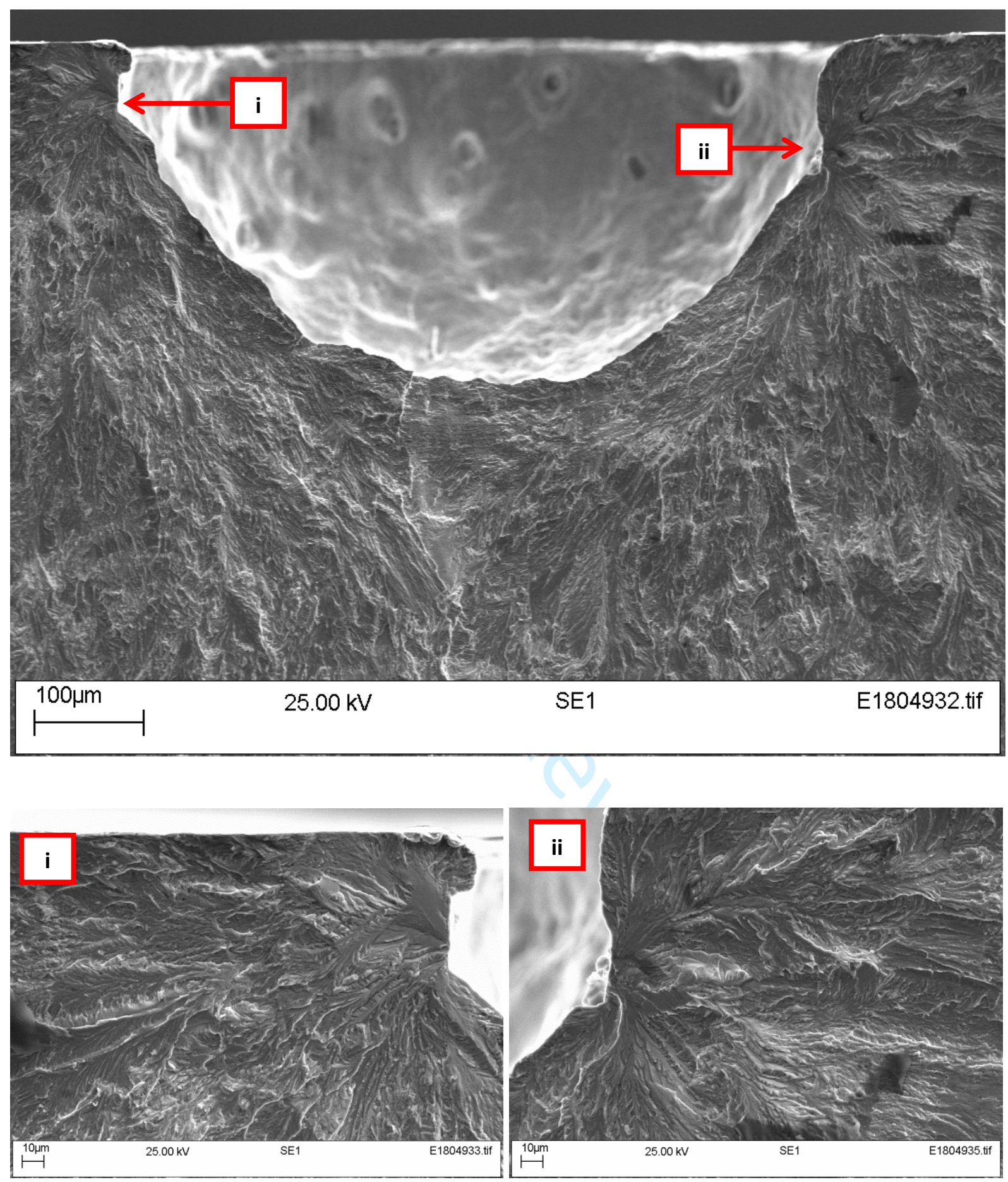

Figure 6: SEM images of crack flank from 'Specimen 2' of quasi-symmetrical pit with AR= 0.92. The images emphasise the two crack initiation sites, $i$ and ii being around the shoulder region of the corrosion pit. Images $i$ and ii are higher resolution images of those sites. 


\section{WILEY-VCH}
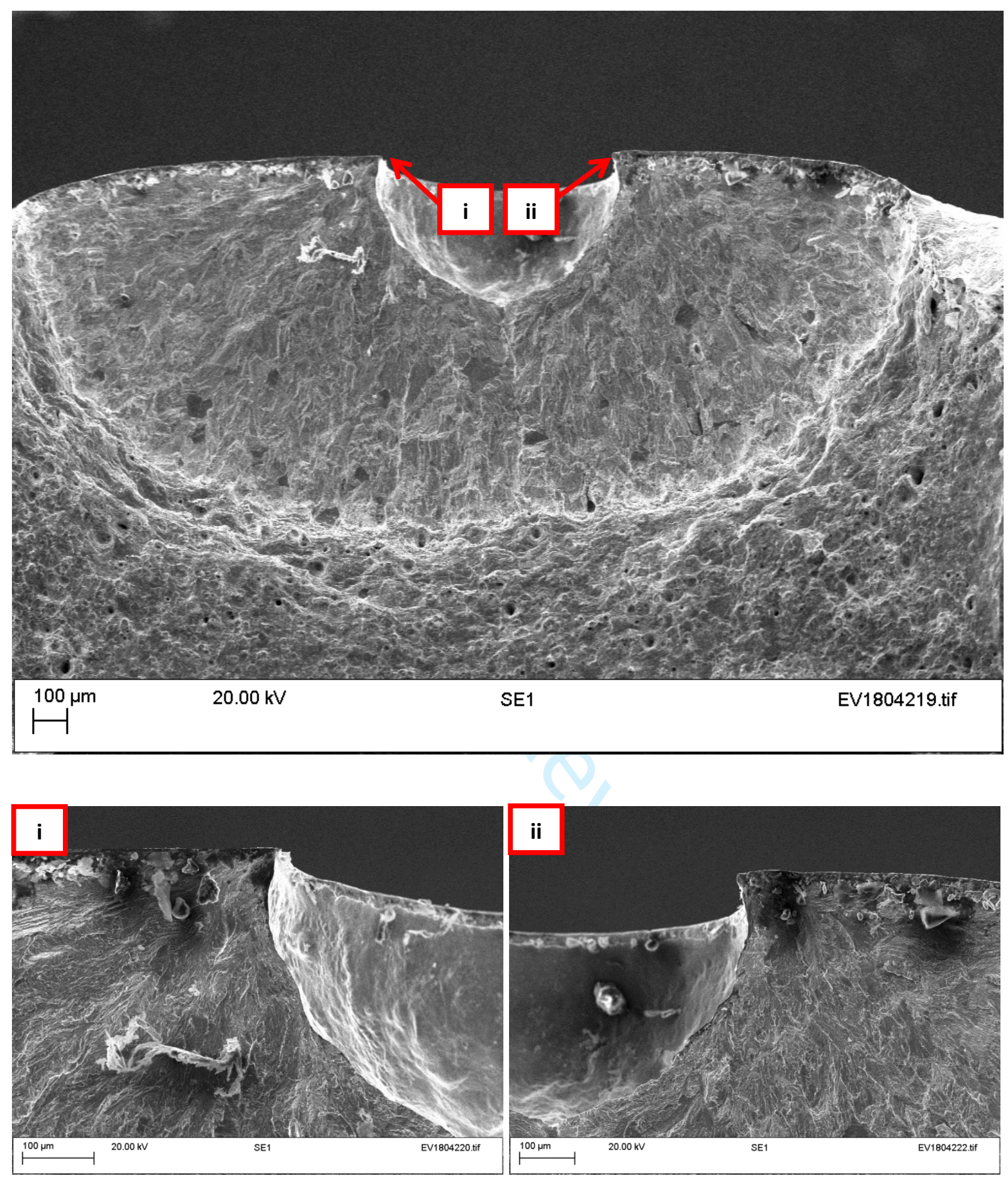

Figure 7: SEM images of crack flank from 'Specimen 3' of deep pit with $A R=1.26$. The images emphasise the two crack initiation sites, $i$ and ii being at the mouth of the corrosion pit. Higher resolution images of sites $i$ and ii where cracks initiated are presented. 


\section{WILEY-VCH}

\subsection{FEA}

\subsubsection{The stress-strain hysteresis loop at the pit base}

Elastic-plastic FE simulations relating to samples 1-3 (vis. shallow, quasi-symmetrical and deep pit specimens) containing a single central corrosion pit were carried out. Cyclic loading parameters used in the model were identical to those used in tests, i.e. maximum load of 300 $\mathrm{MPa}$ and $\mathrm{R}$ ratio of 0.1 (i.e. stress range $(\Delta \sigma)$ of $270 \mathrm{MPa}$ ). The stress-strain hysteresis loop in the loading direction (refer to Figure 4) at the base of the pits was obtained from the results (Figure 8). The maximum stress and local stress ratio is provided on each plot for pits 1-3. As shown in Figure 8, a large plastic strain occurs during the first cycle; thereafter the loops converge upon reaching a stable condition. It is known that multiple rather than single cracks can initiate at the locations of plastic deformation around the pit [24]. Of particular interest is that, although the applied stress ratio is 0.1 (i.e. tensile-tensile load) in all cases, the calculated local stress ratio at the pit base is less than 0.1 and becomes compressive, i.e. decreases from 0.27 to -0.4 with increasing the pit depth. The local stress ratio is shown in each graph. It shows that the entire pit base experienced compressive stress even when the minimum stress of 30 MPa was applied to the sample. 


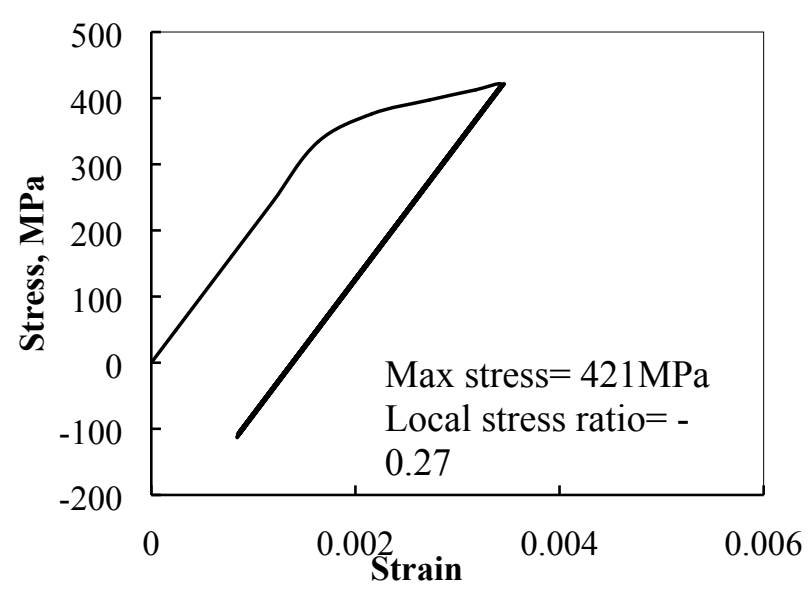

(a)

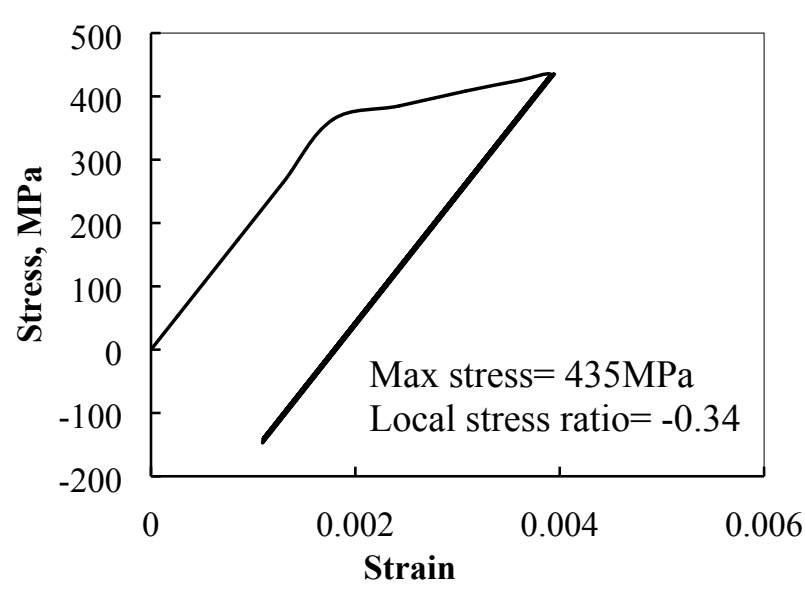

(b)

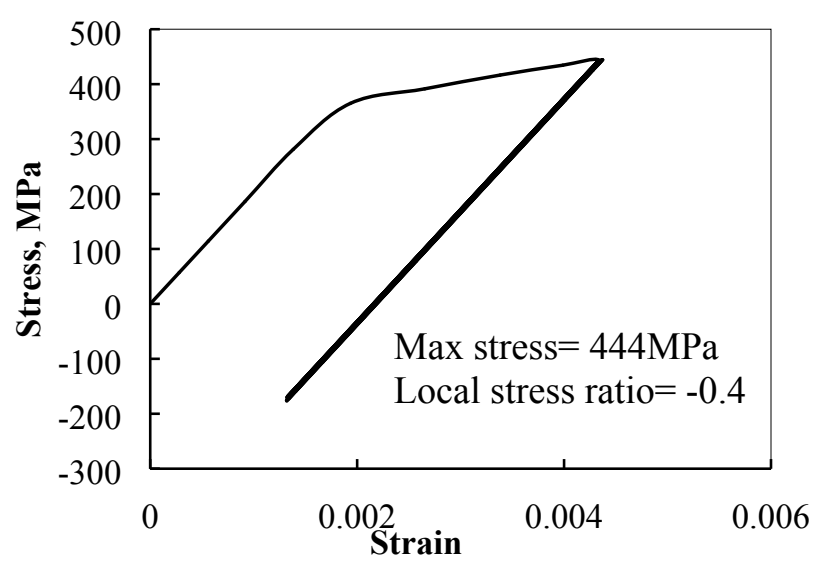

(c)

Figure 8: Local stress $\left(\sigma_{\mathrm{xx}}\right)$-strain $\left(\varepsilon_{\mathrm{xx}}\right)$ hysteresis curves, maximum stress and local stress ratio resulted from FEA for the base of pit. Applied stress ratio was 0.1. Pit aspect ratio (AR) were: a) 0.67 , b) 0.93 and c) 1.2 


\section{WILEY-VCH}

The pit base maximum stress and strain in each sub figure shows clearly that increasing the pit depth has resulted in a slight increase in the maximum stress at the pit base and a large change in the maximum strain, i.e. the effect of pit geometry on local maximum stress and strain.

\subsubsection{Stress Distribution}

Figures 9, 10, 11 and 12 show the stress distribution around the three FEA-simulated pits at different time intervals during the first and second loading cycle, i.e. $1 \frac{1 / 4,1}{112}, 1 \frac{3}{4}$ and finally at end of $2^{\text {nd }}$ cycle. For convenience, only quarter sections are reproduced in these images. As evident from the legend in each case, the stress contours indicate negative stress values meaning that despite the applied load being tensile-tensile, the local stress at the pit mouth or the entire cavity is compressive. It is apparent from the figures that more compressive stress is present for higher aspect ratios/pit depth values. 


\section{WILEY-VCH}
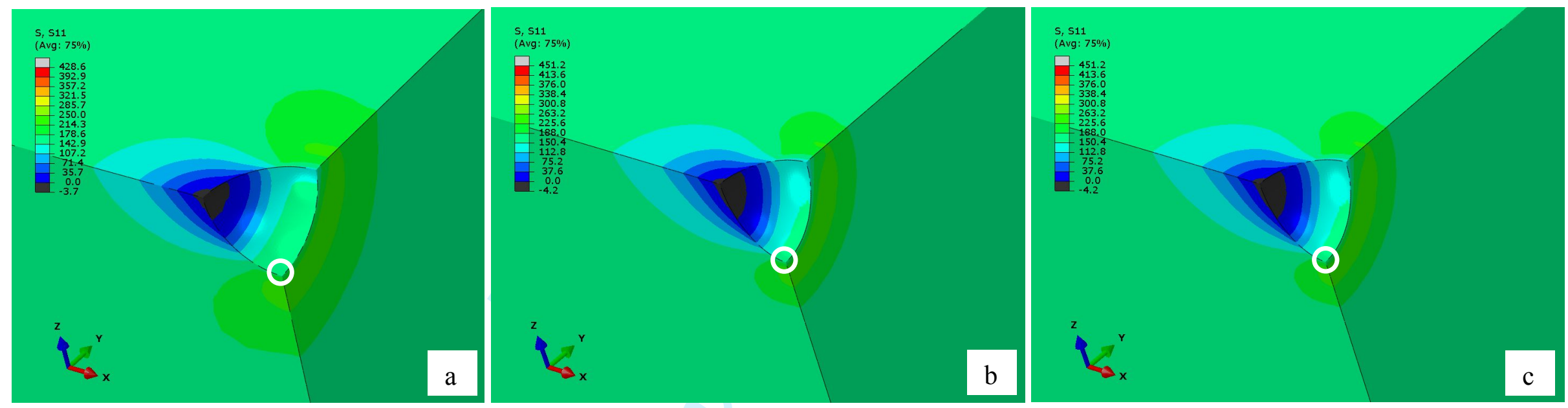

Figure 9 Stress $\left(\sigma_{\mathrm{xx}}\right)$ contours after $1 \frac{1}{4}$ cycle (loading). The $\mathrm{X}$ direction is the loading direction. The pit base is shown by the white circle. (a) Pit $\mathrm{AR}=0.67,(\mathrm{~b})$ Pit $\mathrm{AR}=0.93$, (c) $\mathrm{Pit} \mathrm{AR}=1.2$

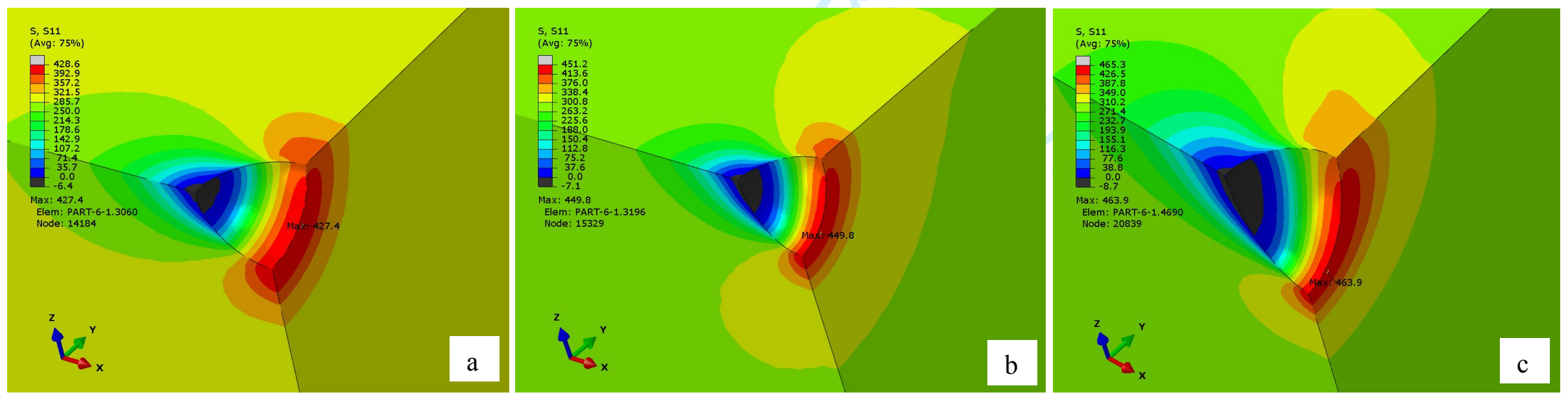

Figure 10 Stress $\left(\sigma_{\mathrm{xx}}\right)$ contours after $1 \frac{1 / 2}{2}$ cycle (maximum applied stress). The $\mathrm{X}$ direction is the loading direction. (a) Pit $\mathrm{AR}=0.67$, (b) Pit $\mathrm{AR}=$ 0.93 , (c) Pit $\mathrm{AR}=1.2$ 
WILEY-VCH
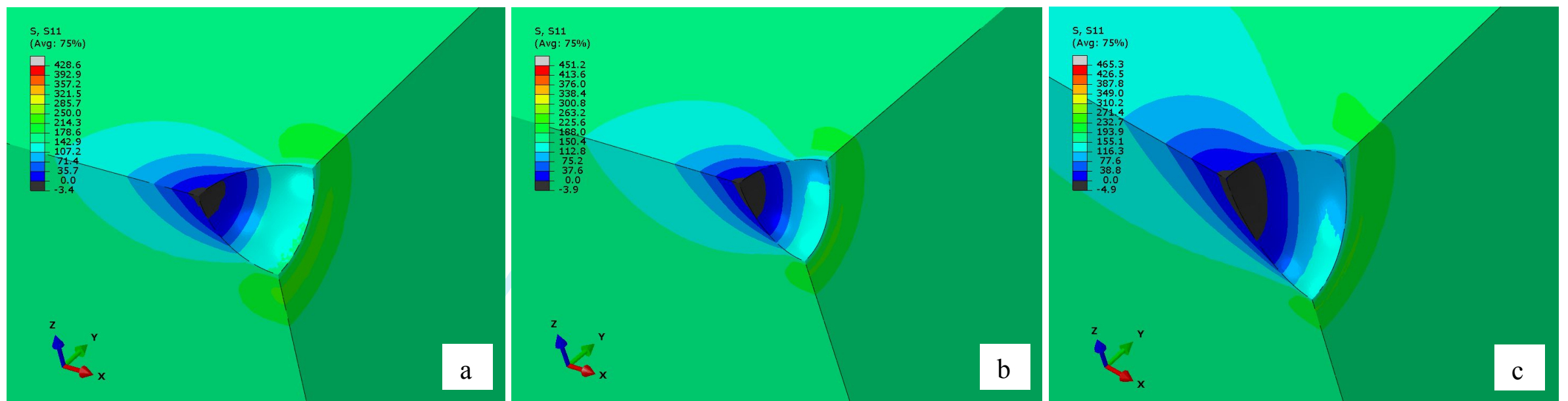

Figure 11 Stress $\left(\sigma_{\mathrm{xx}}\right)$ contours after $13 / 4$ cycle (unloading). The $\mathrm{X}$ direction is the loading direction. (a) Pit $\mathrm{AR}=0.67$, (b) Pit $\mathrm{AR}=0.93$, (c) Pit $\mathrm{AR}=1.2$
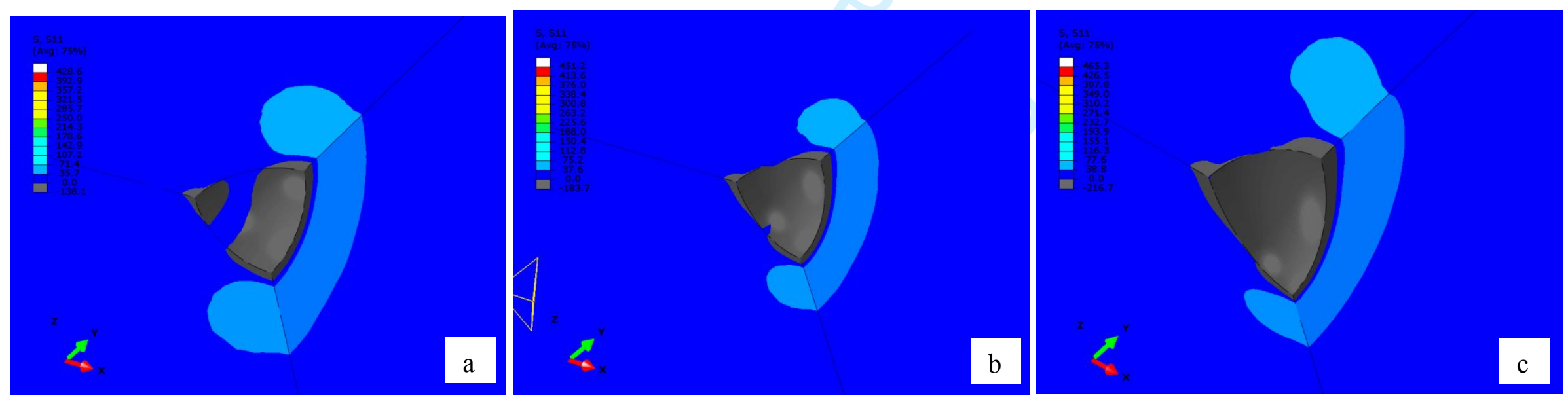

Figure 12 Stress $\left(\sigma_{\mathrm{xx}}\right)$ contours after 2 nd cycle (minimum applied stress). The $\mathrm{X}$ direction is the loading direction. (a) Pit $\mathrm{AR}=0.67$, (b) Pit $\mathrm{AR}=$ 0.93 , (c) Pit $\mathrm{AR}=1.2$ 


\section{WILEY-VCH}

\subsubsection{Strain Maps}

Strain maps relating to the effect of cyclic loading on the different pit geometries were calculated using the maximum applied load. The results are presented in Figures 13-15. The strain maps suggest fairly uniform strain for low AR of corrosion pits but the strain begins to localise near the shoulder and the mouth region as the AR of the corrosion pit increases (i.e. the corrosion pit is more $\mathrm{U}$ shaped). It is interesting to compare the development of strain with that of local stress. The pattern of results suggests that increasing pit aspect ratios tends to relocate the localisation of strain towards the pit mouth. These predictions are in good agreement with the experimental results obtained.

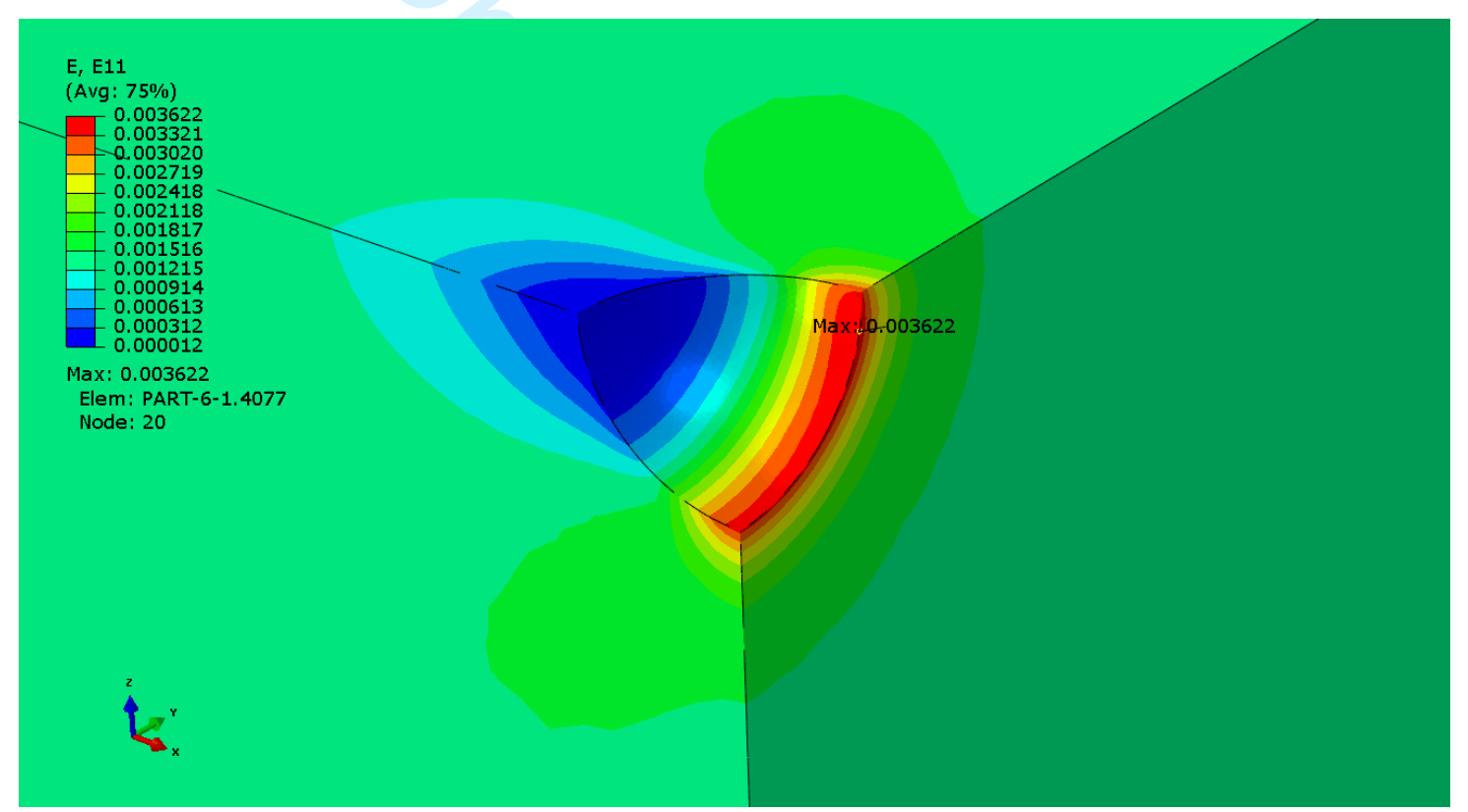

Figure 13: Strain $\left(\varepsilon_{\mathrm{xx}}\right)$ map at the maximum applied load for pit with AR 0.67. It shows that the strain is concentrated uniformly around the centre line. 


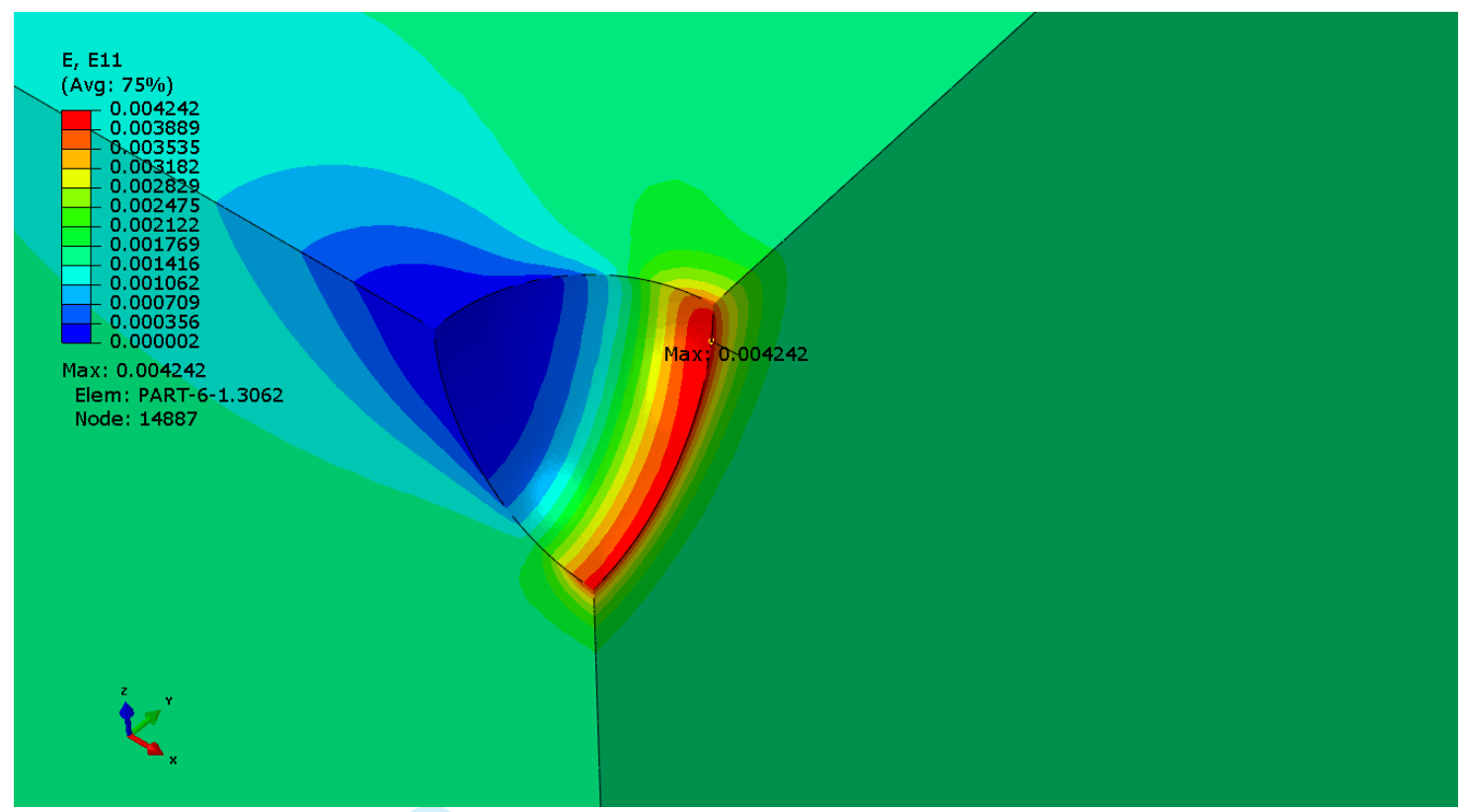

Figure 14: Strain $\left(\varepsilon_{\mathrm{xx}}\right)$ map at the maximum applied load for pit with AR 0.92. The strain in this pit is slightly more concentrated from the shoulder region to the mouth of the corrosion pit.

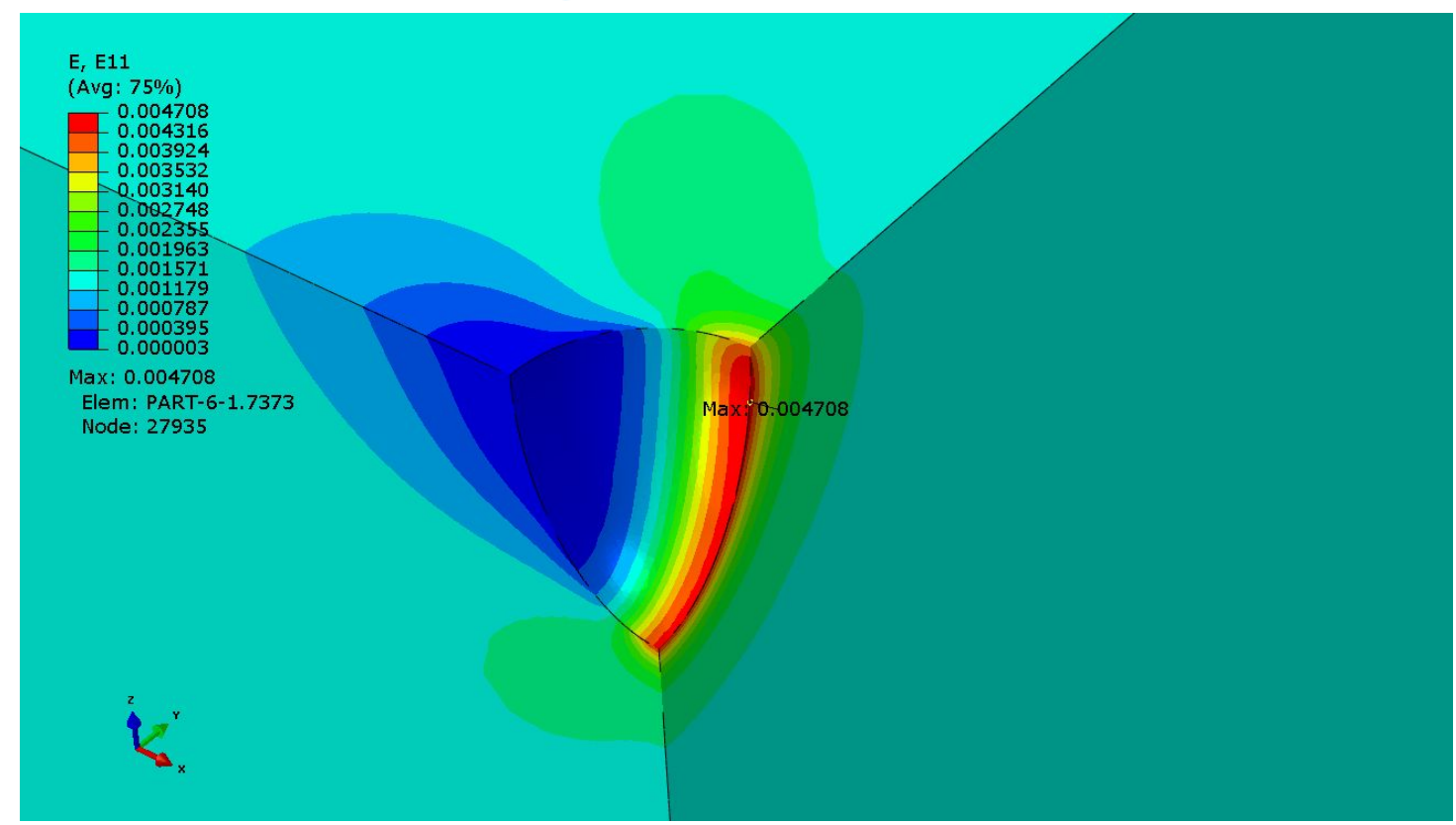

Figure 15: Strain $\left(\varepsilon_{\mathrm{xx}}\right)$ map at maximum applied load for pit with AR 1.2. The strain in this pit is significantly more concentrated near the mouth of the pit. 


\section{WILEY-VCH}

\section{Conclusions}

The effect of pit geometry and cyclic loading and consequential development of local stress and strains at corrosion pits in stainless steel $316 \mathrm{~L}$ have been investigated by fatigue testing, fractography examination and finite element analysis. Based on this study, following conclusions can be drawn.

- From the corrosion fatigue tests of a single corrosion pit and fractography analysis, it is seen that the crack initiated at the base of the shallow pit (aspect ratio, a/c, of 0.67 , where $\mathrm{a}=$ pit depth and $\mathrm{c}=$ half-width). The crack initiation site shifted towards pit shoulder or mouth region as the pit depth-to-width aspect ratio is increased. This was further investigated using finite element analysis of the strain localisation around the corrosion pit.

- Finite element analysis has shown that

- Even when the applied cyclic stress is tension-tension, the local stress in the loading direction at the pit can be tension-compression owing to the plasticity effect. For applied stress ratio of 0.1 , the local stress ratio is decreased from 0.27 to -0.4 with increasing pit depth.

- The magnitude of local compressive stress increases with increasing pit depth. This is due to the increase in the stress concentration factor

- The strain maps for different pit geometries have shown the following crack initiation trends, which are confirmed by the tests in this study

- For a shallow pit, with an aspect ratio of 0.64 , the strain concentration is uniform around the centre of the pit, suggesting that fatigue crack initiation can be anywhere in that region 


\section{WILEY-VCH}

- For intermediate pit aspect ratio of 0.93 , the strain concentration is near the pit shoulder region; the crack initiation site is more likely to take place in that region.

- For larger pit aspect ratio of 1.2 , the strain concentration is near the pit mouth; hence, it is very likely that fatigue crack initiation starts at the pit mouth.

\section{Acknowledgements}

This work is based on research supported by the Lloyds Register Foundation ${ }^{1}$ and the authors greatly acknowledge the financial support by the Foundation. The work was enabled through, and undertaken at, the National Structural Integrity Research Centre (NSIRC), a postgraduate engineering facility for industry-led research into structural integrity established and managed by TWI through a network of both national and international universities.

${ }^{1} A$ charitable foundation, helping to protect life and property by supporting engineering-related education, public engagement and the application of research. www.lrfoundation.org.uk 


\section{WILEY-VCH}

\section{References}

[1] A. Kolios, S. Srikanth, K. Salonitis, Procedia CIRP 2014, 13, 230.

[2] S.X. Li, R. Akid, Eng. Fail. Anal. 2013, 34, 324.

[3] N.O. Larrosa, R. Akid, R.A. Ainsworth, Int. Mater. Rev. 2018, 63, 283.

[4] T. Goswami, D.W. Hoeppner, J. Mech. Behav. Mater. 1997, 8, 169.

[5] C.A. Arriscorreta, Ph.D. Thesis, The University of UTAH, United States of America, 2012.

[6] Y. Kondo, Corrosion 1989, 45, 7.

[7] G.S. Chen, K.C. Wan, G. Gao, R.P. Wei, T.H. Flournoy, Mater. Sci. Eng. A 1996, 219 , 126.

[8] M.R. Sriraman, R.M. Pidaparti, J. Mater. Eng. Perform. 2010, 19, 7.

[9] R.W. Hertzberg, R.P. Vinci, J.L. Hertzberg, Deformation and Fracture Mechanics of Engineering Materials, 5th ed., John Wiley \& Sons, Hoboken, New Jersey 2012.

[10] D.A. Horner, B.J. Connolly, S. Zhou, L. Crocker, A. Turnbull, Corros. Sci. 2011, 53, 3466.

[11] B.M. Schönbauer, A. Perlega, U.P. Karr, D. Gandy, S.E. Stanzl-Tschegg, Int. J. Fatigue 2015, 76, 19.

[12] J. Ma, B. Zhang, J. Wang, G. Wang, E.H. Han, W. Ke, Corros. Sci. 2010, 52, 2867.

[13] M. Cerit, Corros. Sci. 2013, 67, 225.

[14] A. Turnbull, L. Wright, L. Crocker, Corros. Sci. 2010, 52, 1492.

[15] Z.T. Mu, D.H. Chen, Z.T. Zhu, B. Ye, Adv. Mater. Res. 2010, 152-153, 1115.

[16] M. Cerit, K. Genel, S. Eksi, Eng. Fail. Anal. 2009, 16, 2467.

[17] J.K. Paik, J.M. Lee, M.J. Ko, Proc. Inst. Mech. Eng. Part M J. Eng. Marit. Environ. 2004, 42, 1161.

[18] A. Turnbull, L.N. McCartney, S. Zhou, Scr. Mater. 2006, 54, 575.

[19] A. Turnbull, D.A. Horner, B.J. Connolly, Eng. Fract. Mech. 2009, 76, 633.

[20] A. Rajabipour, R.E. Melchers, Corros. Sci. 2013, 76, 292.

[21] F. Farhad, X. Zhang, D. Smyth-Boyle, Proc. Inst. Mech. Eng. Part C J. Mech. Eng. Sci. 2018, 233, 1771.

[22] C. Evans, Ph.D. Thesis, University of Manchester, United Kingdom, 2016.

[23] A. Dutta, S. Dhar, S.K. Acharyya, J. Mater. Sci. 2010, 45, 1782.

[24] A.T. Htoo, Y. Miyashita, Y. Otsuka, Y. Mutoh, S. Sakurai, Int. J. Fatigue 2016, 88, 19. 